\title{
Effects of the Long Non-Coding RNA HOST2 On the Proliferation, Migratic Invasion and Apoptosis of Human Osteosarcoma Cells
}

\author{
Wei Wang Xiao Li Fan-Bin Meng \\ Chun-Yang Yang \\ Department of Orthopaedics, Linyi People's Hospital, Linyi, P.R. Ch \\ Key Words \\ Long non-coding RNA-HOST2 - Osteosarcon liferation - Migration - Invasion • \\ Apoptosis
}

Abstract

Background/Aims: This study aimed HOST2 (Inc-HOST2) on the proliferati cells. Methods: Osteosarcor selected. Human osteosarco and cultured; MG-63 cell subsequent experiments transfection), si-CON (tr. with small interfe reaction (qRT-P cells. Cell gro time was gr $\mathrm{n}$, invasion and apoptosis of osteosarcoma lines (saOS2, HOS, U2OS and MG-63) were collected Transwe ays. C optosis and cell cycle progression of osteosarcoma cells were detected in flo metry with annexin V/PI double staining and PI staining, respectively. Results: vel o. HOST2 expression in the si-Inc-HOST2 group was significantly decreased $\mathrm{a} / \mathrm{o}$ inat in the blank and si-CON groups. The OD values in the si-Inc-HOST2 group antly lower than those in the blank and si-CON groups. Compared to the blank si-CON groups, the si-Inc-HOST2 group presented significant decreases in the colony in er and healing rates after scratching. The number of invasive cells in the si-Inc-HOST2 up was significantly less than that in the blank and si-CON groups. In the si-Inc-HOST2 group, the cell cycle was mainly halted in the G1 phase, and the apoptosis rate and doubling time in this group were significantly higher than those in the blank group and si-CON group. Conclusions: Inhibition of Inc-HOST2 could suppress the proliferation, migration, and invasion and promote the apoptosis of osteosarcoma cells. 


\section{Introduction}

Osteosarcoma is a primary malignant tumor of the skeleton characterized by the direct formation of immature bone or osteoid tissue by tumor cells. Osteosarcoma rarely arises in soft tissue [1]. Osteosarcoma is the most common primary tumor of the bone that typically affects the long tubular bones of children and adolescents. The prognosis of patients $w$. high-grade osteosarcoma who are treated with surgery alone has been very poor with 5 -year survival rates below 20\% [2]. The age distribution of osteosarcoma is the greate during the skeletal growth period of adolescence [3]. In these years, the 5-year sur rate was only $30-40 \%$ despite the use of surgery, and radiation combined with dimer chemotherapy, [4]. Therefore, finding advanced diagnostics and therapies for oste is critical for future studies. Many reports have described the development of tu. regard to non-coding RNAs [5].

Long non-coding RNAs (lncRNAs) are RNA molecules that are long length and lack an open reading frame. Recent studies have provided ev play significant roles in a variety of cellular processes via interas gene regulatory systems; additionally, alterations in their $\mathrm{c}^{\mathrm{ell}}$ - or tiss and/or their primary or secondary structures are thov metastasis and invasion [6]. With the advances of high-re parallel sequencing technologies, IncRNAs have gained have been found to play important roles in the diagnosis a especially in the tumorigenesis and progres small cell lung cancer and papillary thyroid canc proven to support the notion that lncRNAs can diagnosis of multiple diseases [10-12]. Rang and sequencing of the corresponding express some of these transcripts, namely, hur novel gene, HOST2 contains multiple an obvious open reading fram $[12]$. 1 and invasion in epithelial ov, ance. f human

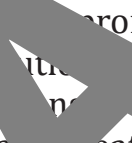
rers, such as human non9]. Mored er, increasing evidence has ed in plasma as biomarkers for the al. that database analyses, cloning nce tags provided details regarding cer-specific transcripts (HOSTs). As a romote tumor cell proliferation, migration rting its functions in key aspects of biological behaviors, and a bioinformat lysis revealed that HOST2 could bind the potent tumor suppressor microRNA let whic erified to target HOST2 [14]. LncRNAs may be used as novel candidate bior kers for tne clinical diagnosis and treatment of some diseases and could serve as pote not been charact osteosarcoma samples to date. In this study, we aimed to investigate the inc-HOST2 on the proliferation, migration, invasion and apoptosis of osteosarcoming s.

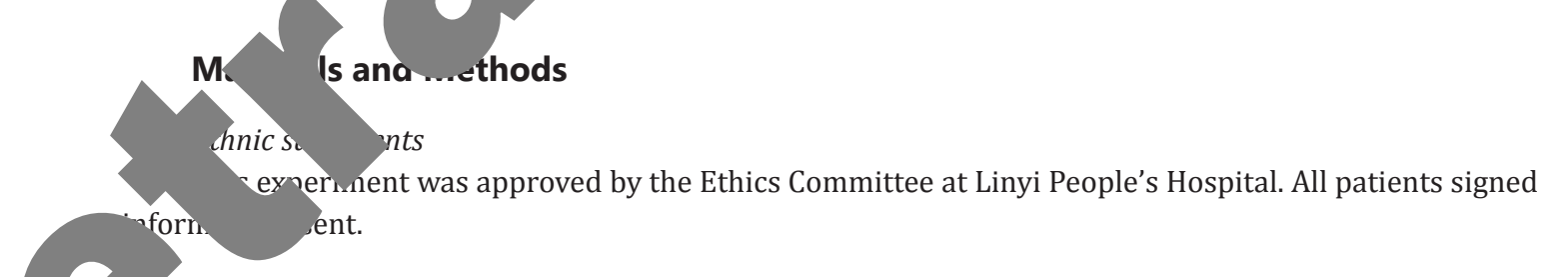

\section{Study subjects}

Setween January 2008 and January 2014, osteosarcoma tissues and adjacent normal tissues (at least m away from the tumor site) were obtained from 52 osteosarcoma patients who underwent surgery at Linyi People's Hospital. Tissue samples were immediately frozen in liquid nitrogen for further use. There were 27 females and 25 males, and the median age of the cohort was 15.2 years old. All the osteosarcoma patients were confirmed by postoperative pathological examinations. The histological types of the 52 samples contained osteogenic tissue $(n=25)$, cartilaginous tissue $(n=16)$, and fibrous tissue $(n=11)$.

\section{Cell culture and selection}

The osteosarcoma SaOS2, HOS and U2OS cell lines were purchased from American Type Culture Collection (ATCC) and cultured in Dulbecco's Modified Eagle's medium (DMEM) (Gibco, Gaithersburg, MD,

\section{e}




\section{Cellular Physiology and Biochemistry \\ Cell Physiol Biochem 2017;43:320-330 \\ \begin{tabular}{l|l}
\hline DOI: 10.1159/000480412 & (C) 2017 The Author(s). Published by S. Karger AG, Basel
\end{tabular} \\ Published onlIne: August 31, 2017 www.karger.com/cpb \\ Wang et al.: Effects of Lncrna-HOST2 On Osteosarcoma Cells}

USA) with 10\% fetal bovine serum (FBS) (HyClone, USA). The osteosarcoma MG-63 cell line (purchased from Shanghai cell bank) was cultured in 1640 medium (Gibco, Gaithersburg, MD, USA) with 10\% FBS. Cells were incubated at $37{ }^{\circ} \mathrm{C}$ in an atmosphere containing $5 \% \mathrm{CO}_{2}$ to approximately $70 \%$ confluence and then passaged. After removal of the original medium, the cells were rinsed twice with phosphate-buffered saline (PBS), digested in 0.25\% trypsin (Gibco, Gaithersburg, MD, USA), and resuspended in DMEM or 16 medium (as appropriate) containing $10 \%$ FBS to form a single-cell suspension for routine passages. Cells the logarithmic growth phase were used for our experiment.

\section{Cell transfection and grouping}

MG-63 cells in the logarithmic growth phase were digested, counted, and seeded in a density of $2 \times 10^{5}$ cells per well to approximately $50 \% \sim 60 \%$ confluency. Then, the cells wer transfected with Lipofectamine 2000 according to the manufacturer's instructions CA, USA). The cells were transfected with either negative control siRNA or 50 nmol, (purchased from Shanghai Gene Pharma Co., Ltd, China). The transfected cells were in $5 \% \mathrm{CO}_{2}$. After 4 to 6 hours, the transfection solution was replaced with fresh culture m in the wells was removed and replaced with 1640 medium containing $10 \%$ FBS fo Cells in the wells were cultivated for another 24 to 48 hours. The were div nto three groups: the blank (without any transfection), si-CON (transfected by ne siRN hilnc-HOST2 (transfected by small interference lnc-HOST2 siRNA) groups. The s sec the lnc-HOST2 siRNA was 5'-GACUAAACAAGGUCUUAAUTT-3', and the antisense sequence wà _AA, CCUUGUUUAGUTCC-3'. The sense sequence of the negative control siRNA was ' 'UCUCCGAACC 'CACGUTT-3', and the antisense sequence was 5'-ACGUGACACGUUCGGAGAATT-3'. Ma 'le, a GAPL RNA group was used as a positive control with the sense sequence 5'-GUAUGACA CUCAAGTI-3' and the antisense sequence 5'-CUUGAGGCUGUUGUCAUACTT-3' [15]. These seque wo igned and constructed by GenePharma Co., Ltd. (Shanghai, China). In addition, we conducte cyt to detect the transfection efficiency, which indicated that among $2.0 \times 10^{5}$ cells per the efficiency was $97.3 \%$, and $70 \%$ of the signal was detected.

Quantitative real-time polym

Total RNA was extracted frop using an miRNeasy Mini Kit $(\mathrm{C}$ ren den, Germany). The concentration and purity of RNA were detected by measuring the violet ab ance at $260 \mathrm{~nm}$ and $280 \mathrm{~nm}$ (optical density, OD260/OD280 ratio) using an ultraviolet s the RNA had high purity for ropho'meter. An OD260/OD280 ratio between 1.7 and 2.1 indicated that texperiments. The cDNA template was synthesized using reverse transcription witb Time PCR syster 19 conditions were as follows: initial denaturation at $95^{\circ} \mathrm{C}$ for 10 min followed by 40 cycles den at at $95^{\circ} \mathrm{C}$ for $10 \mathrm{~s}$, annealing at $60^{\circ} \mathrm{C}$ for $20 \mathrm{~s}$, and extension at $72{ }^{\circ} \mathrm{C}$ for 34 s. The re syst mprised $10 \mu \mathrm{l}$ of SYBR Premix Ex Taq ${ }^{\mathrm{TM}}$ II, $0.8 \mu \mathrm{l}$ of PCR Forward Primer (10 yM), 0.8 TCR Reverse Primer $(10 \mu \mathrm{M}), 0.4 \mu \mathrm{l}$ of ROX Reference Dye, $2.0 \mu \mathrm{l}$ of cDNA template, and of ste stilled water. According to the full-length gene sequence of HOST2 IncRNA, specific for HO 2 IncRNA were designed using Primer 5, and reference primers were used as previously 6]. The primer sequences (synthetized by Shanghai Invitrogen Biotechnology Co., Ltd., Ighar, china) were as follows: forward primer for lnc-HOST2, 5'-CTCAAATCAATCACGACCCT-3', reverse
in for Inc-HOST2 was 5'-AATGTAGCAGGACGAGCC -3'; forward primer for the reference gene GAPDH 2. ACCCATGGCAAATTCCATGGCA-3', reverse primer for GAPDH, 5'-TCTAGACGGCAGGTCAGGTCCACC-3'. sing GAPDH gene as a reference, the relationship between the expression of the target gene in the experimental group and the control group was expressed using the $2^{-\Delta \Delta \mathrm{Ct}}$ method $\left(\Delta \Delta \mathrm{CT}=\Delta \mathrm{Ct}_{\text {experimental group }}{ }^{-}\right.$ $\Delta \mathrm{Ct}_{\text {control group }} . \Delta \mathrm{Ct}=\mathrm{Ct}_{\text {Inc-HOST2 }}-\mathrm{Ct}_{\mathrm{GAPDH}}$, where $\mathrm{Ct}$ is the number of cycles before the fluorescence intensity of the reaction reached the preset threshold, which means at that time amplification was in log phase).

\section{CCK-8 assay}

When transfected reached approximately 80\% confluence, MG-63 cells were rinsed with PBS twice and digested into a single-cell suspension with $0.25 \%$ trypsin. After they were counted, the cells were seeded in a 96-well plate at a density of $3 \sim 6 \times 10^{3}$ cells per well in a volume of $200 \mu \mathrm{l}$ per well. Each condition was

\section{KARGER}




\section{Cellular Physiology Cell Physiol Biochem 2017;43:320-330

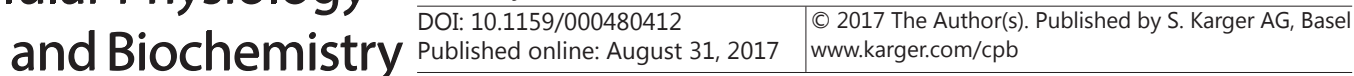 \\ Wang et al.: Effects of Lncrna-HOST2 On Osteosarcoma Cells}

repeated in 6 wells. After the cells were cultured for $24 \mathrm{~h}, 48 \mathrm{~h}$ and $72 \mathrm{~h}$, the plate was removed from the incubator, and $10 \mu \mathrm{l}$ of CCK8 was added per well. Then, the cells were cultured for another $2 \mathrm{~h}$. The optical density (OD) of each well was detected at $450 \mathrm{~nm}$ using an enzyme-linked immunosorbent assay (ELISA). Every experiment was repeated 3 times. A cell survival curve was drawn with time on the abscissa and OD on the ordinate.

\section{Cell Doubling Test}

When density of MG-63 cells reached approximately 80\%, the cells were trypsinized with 0.2 trypsin and then made into a single-cell suspension. After counting, the suspension was seeded in a 6 plate with $2 \times 10^{3}$ cells per well and a volume of $200 \mu$ l per well. A total of 6 replicates in set. In addition, the cells were cultured in incubator for 7 days to digest and count. Doublin $[\lg 2 /(\operatorname{lgN} 0-\lg \mathrm{N} 7)] \times 24(\mathrm{~N} 0$ indicates the cell number at day $0 ; \mathrm{N} 7$ indicates the cell $\mathrm{n} / \mathrm{b}$ experiment was repeated 3 times.

\section{Colony formation assay}

Cells cultivated on an LB plate were digested, centrifuged, counted and re-s Then, the cells were seeded at a concentration of 500 cells per cultur $\quad(10 \mathrm{~cm})$ a tured for 2 weeks at $37^{\circ} \mathrm{C}$ in an incubator containing $5 \% \mathrm{CO}_{2}$. After removal of the me are rin. fixed with $4 \%$ paraformaldehyde at room temperature for $20 \mathrm{~min}$ a $\quad$ ain $\quad$ rystal violet solution for $60 \mathrm{~min}$. The stain was slowly removed. When the dishes were ai the amber of clones among more than 50 cells was counted under a microscope. $T$ xperiment $w$ veated 3 times.

\section{Scratch test}

After transfection for $48 \mathrm{~h}, \mathrm{MG}-63$ cells from al plate at a density of $1 \times 10^{5}$ cells per well to approxima scratches were made using a $200-\mu$ l pipette tip rate of a scratch was calculated as follows: \{ h\} $\times 100 \%$. The assay was conducted 3 tim

\section{Transwell assay}

Matrigel (Corning, USA) A total volume of $30 \mu \mathrm{l}$ of $\mathrm{d}$ 3 times $(15 \mu \mathrm{l}, 7.5 \mu \mathrm{l}, 7.5 \mu$ micro-wells in the bottom of were suspended a medium contain 18 ${ }^{\circ} \mathrm{C}$ in an atm here ta gro collected and seeded into a 6-well $90 \%$ aence. Four horizontal and four vertical eral scratches were measured. The healing dth at $\mathrm{h}$ - scratch width at $24 \mathrm{~h}$ )/scratch width at 0 at. the migration of the cells in three groups. The mer s we $95 \%$ ethanol for 15 to 20 min and stained with a crystal violet solution for $5 \% \mathrm{CO}_{2}$ non-migratory cells in the upper ight at $4^{\circ} \mathrm{C}$ and diluted with serum-free 1640 medium (1:3).
d Matris as added to the upper chamber of every transwell chamber th 10-min incubation steps between each addition to evenly cover all the chamber. At $48 \mathrm{~h}$ after transfection, MG-63 cells from all the groups in tru upper chamber of the Transwell (Corning, USA). A total of $0.5 \mathrm{ml}$ of 1640 as added to the lower chamber of a 24 -well plate. After $48 \mathrm{~h}$ of culture at 37 $1 / \min$. A $\quad$ inserts were rinsed, cells were counted and photographed at high magnification using an d mic. The collected data were the means of the number of cells under 5 randomly selected vision. . number of cells that migrated through the Matrigel was regarded as the evaluation index The experiment was repeated 3 times.

\section{Dlow cytometry with Annexin V/PI double staining}

After transfection for 48 h, MG-63 cells were digested with trypsin without ethylenediamine rraacetic acid (EDTA), collected in the flow tube (both of supernatant and solution contained a few dead cells and apoptotic cells, and all these were included in), and centrifuged at $1000 \mathrm{r} / \mathrm{min}$ for $5 \mathrm{~min}$. Then, the supernatant was removed. Cells were rinsed with ice-cold PBS 3 times and centrifuged before the supernatant was discarded. In accordance with the Annexin-V-FITC apoptosis determination kit (Sigma, St. Louis, Missouri, USA), every tube of cells was added to $150 \mu \mathrm{l}$ Binding buffer and $5 \mu$ l Annexin-V-FITC and evenly mixed. After incubation in the dark at room temperature for $15 \mathrm{~min}$, another $100 \mu \mathrm{l}$ of Binding buffer and $5 \mu$ PI stain (Sigma, St. Louis, Missouri, USA) was added to each tube, which was then shaken. The negative control group did not receive Annexin V treatment. Cell apoptosis was detected using flow cytometry (Coulter Corporation Co., Ltd., California, USA) within 1 hour of staining as soon as possible. The

\section{KARGER}




\section{Cellular Physiology and Biochemistry Publisned \begin{tabular}{l|l} 
DOI: 10.1159/000480412 31,2017 & $\begin{array}{l}\text { ( ) } 2017 \text { The Author(s). Published by S. Karger AG, Basel } \\
\text { www.karger.com/cpb }\end{array}$
\end{tabular} \\ Wang et al.: Effects of Lncrna-HOST2 On Osteosarcoma Cells}

results of the flow cytometry experiments were displayed as 4 quadrants, in which the upper right quadrant indicated advanced apoptosis rate; the lower right quadrant represents the apoptosis rate during the early stages; the upper left quadrant represents dead cells; and the lower left quadrant represents living cells. The apoptotic rate was calculated as follows: apoptotic rate of cells in the advanced stage + the apoptotic rate of cells in early stage. This experiment was repeated 3 times.

\section{Flow cytometry with PI staining}

After transfection for $48 \mathrm{~h}, \mathrm{MG}-63$ cells in all the groups were collected and rinsed with ice-cold 3 times and then centrifuged before the supernatant was removed. The cell suspension uns adjust approximately $1 \times 10^{5}$ cells $/ \mathrm{ml}$. Cells were fixed in $1 \mathrm{ml}$ of ice-cold $75 \%$ ethanol at $4{ }^{\circ} \mathrm{C} \mathrm{o}$ staining, cells were rinsed with PBS twice, and the supernatant was removed. The cells were $100 \mu \mathrm{l}$ RNaseA and immersed in a $37^{\circ} \mathrm{C}$ water bath for $30 \mathrm{~min}$ in the dark followed by st ir wit. $\mathrm{PI}$ and incubating the mixture at $4^{\circ} \mathrm{C}$ for $30 \mathrm{~min}$ in the dark. Flow cytometry (Coulter of California, USA) was used to detect the red fluorescence at $488 \mathrm{~nm}$ to identify the pha. The experiment was repeated 3 times.

\section{Statistical analysis}

SPSS 21.0 software (SPSS Inc., Chicago, IL, USA) was applied were expressed as the mean \pm standard deviation (SD). Compariso using a $t$ test (either the independent sample $t$ test or paired $t$ test). 0 was used to compare multiple groups. $P<0.05$ was co ered statistic.

\section{Results}

Expression of Inc-HOST2 in the osteosarco

The results indicated that compar of lnc-HOST2 in the osteosarcoma tis correlation between the expre'sion o of osteosarcoma patients we using a $t$ test and among m? no significant correlatio etw zea

\section{s)} of and the clinicopathological characteristics irisons between two groups were conducted roups using an $F$ test. As shown in Table 1, there was etw expression of lnc-HOST2 and age, gender, or histopathologic subtype ssteosarcuna among the patients (all $P>0.05$ ). The above results suggested that lnc-HOS vas hly expressed in the osteosarcoma tissues; therefore, a close correlation veen the expression of lnc-HOST2 and the occurrence and development or coma.

Expre no, sT2 in four cell lines

Th osar cell lines SaOS2, HOS, MG-63 and U2OS were cultured. qRT-PCR was $r$ letect the expression of lnc-HOST2. own ih 2, lnc-HOST2 was expressed in t. S2 HOS, MG-63 and U2OS cell lines. The vpre. of lnc-HOST2 was highest in the MGcell line and lowest in the U2OS cell line. Thus, ments.

Expression of Inc-HOST2 in MG-63 cells among the three groups

The expression of si-lnc-HOST2 in MG63 cells was tested using qRT-PCR. The results showed that after transfection with si-lnc-HOST2, the expression of lnc-HOST2 in this MG-63 cell line was significantly decreased compared with

\section{KARGER}

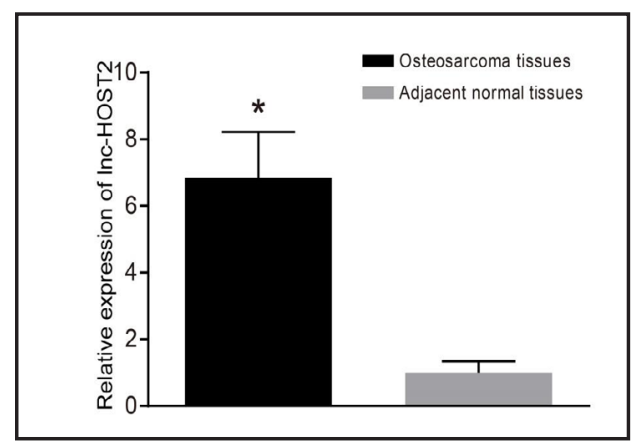

Fig. 1. Expression of lnc-HOST2 in osteosarcoma and normal adjacent tissues. * refers to $\mathrm{P}<0.05$ compared with adjacent normal tissues. 
that in the blank and si-CON groups (both $P<0.05$ ). There was no significant difference between the blank group and si-CON group (both $P>0.05$ ) (Fig. 3).

\section{Effect of Inc-HOST2 on} the proliferation of $M G$ 63 cells among the three groups

The CCK8 assay was conducted to detect the proliferation of MG-63 cells after knocking down the expression of lnc-HOST2. The OD value (which reflects the proliferation rate) was calculated, and proliferation curves at 24 hours, 48 hours and 72 hours were constructed. As shown in the results of the CCK8 assay (Fig. 4A), the MG-63 cells proliferation in the $:$ HOST2 group was obviously slower down. Cor rea with the blank group and the si-CON group, silnc-HOST2 group had significantly decr ues at $48 \mathrm{~h}$ and $72 \mathrm{~h}$. The proliferatior $1 \mathrm{v} 3$ cens was significantly inhibited when lnc of ression was inhibited (both $P<\quad$ Th significant difference in cell pr tion bucveen the blank group and si-CON gr p ( The results of the doubling time ex iment hated that the si-lnc-HOST2 group $(36 \pm 0.7$ ) showed a longer doubling time than the and the blank 4B). It was sh si-lnc-HOST2 group had a higher cell $\mathrm{mb}$ ha we blank and si-CON groups over th he $d \mathrm{~h} h$ of culturing (48 or $72 \mathrm{~h}$ ), $y$ 'hich in ad that si-lnc-HOST2 slowed the growth $63 \mathrm{c}$ The results mentioned above indicate wn-resalating lnc-HOST2 inhibited the prolifG-63 cells.

\section{affect of Inc-HOST2 on colony formation among the three groups}

The results of the colony formation assay were as follows. The number of MG-63 cell colonies in the si-lnc-HOST2 group was significantly decreased compared with the numbers in the blank group and si-CON group $(P<0.05)$, while there was no significant difference between the blank group and si-CON group $(P>0.05)$. The results suggested that downregulation of lnc-HOST2 inhibited the growth of MG63 cells (Fig. 5).
Table 1. Correlations between the relative expression of lncRNAHOST2 and clinicopathological characteristics of patients with osteosarcoma. IncRNA-HOST2, long non-coding RNA-HOST2; t, the value of independent sample t test; $F$, the test value of one-way $\begin{array}{lllll} & & & & \\ \text { Characteristic } & n & \text { IncRNA-HOST2 expression } & \text { t/F } & P\end{array}$

$\begin{array}{rrr}1.076 & 0.2^{2}\end{array}$

$207.11 \pm 1.49$

32

$6.69 \pm 1.29$
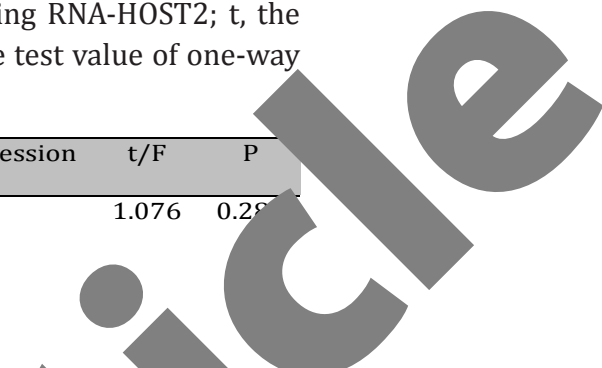

(1)

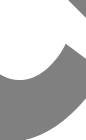
( ( 


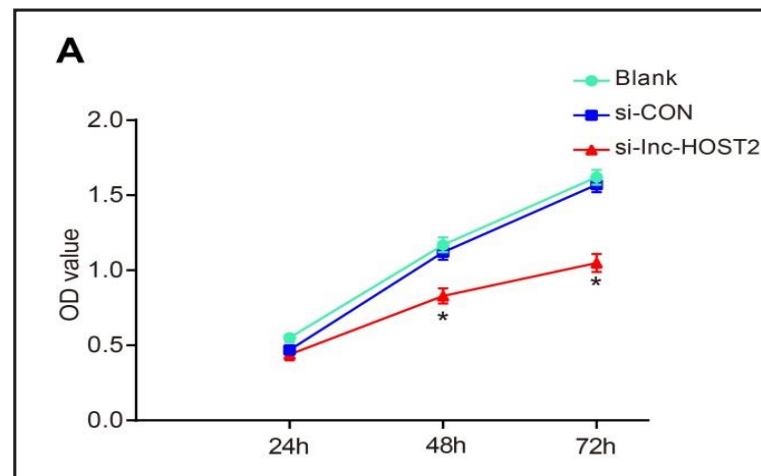

B

Fig. 4. Cell proliferation (A) and doubling time (B) (as detected using the CCK-8 assay) the three transfected groups. * refers to $\mathrm{P}<0.05$ versus the blank group and si-CON $g$

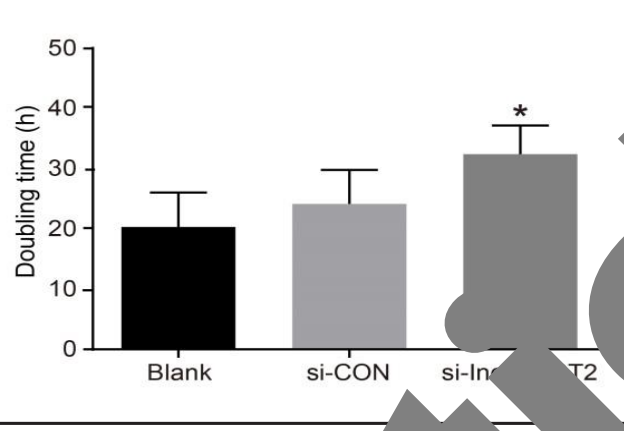
3 cells

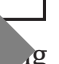
the three transfected groups.* refers to P<0.05 versus the blank group and si-con

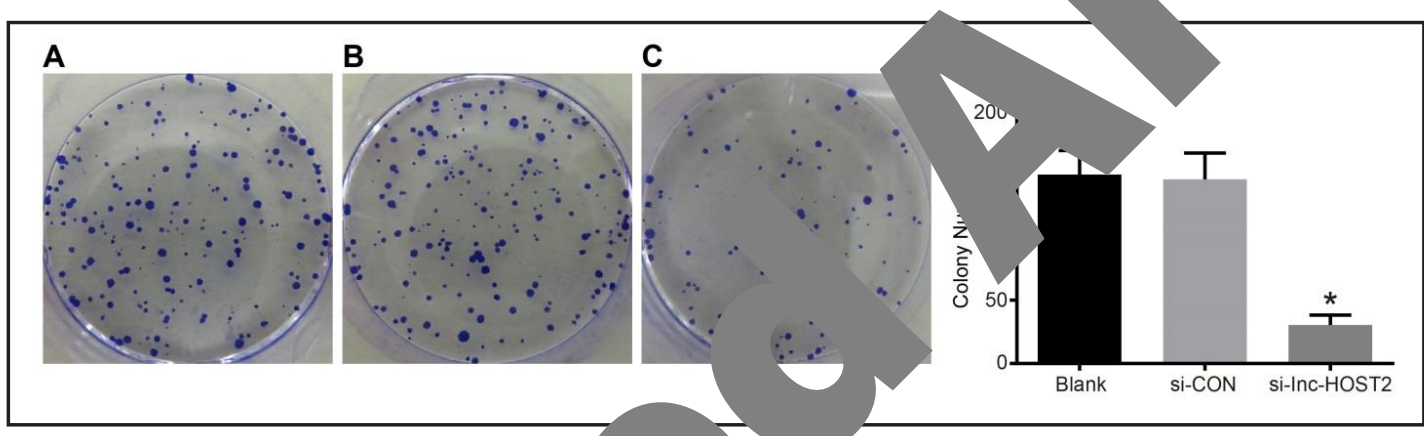

Fig. 5. Cell growth (A) and colony number of 3 cells as detected using the colony formation assay. * refers to $\mathrm{P}<0.05$ compared with the blank

Effect of Inc-HOST2 on th

As shown in Fig. 6, aft 40 . ation of 1 G-63 cells among the three groups

yation, the healing rates after scratching the MG-63 si-CON group were $(73.56 \pm 2.43) \%$ and $(71.05 \pm$ cell monolayers in the $3.69) \%$, respectively $(P$ group was $(51.84+257$
15). Thealing rate of scratch of MG-63 cells in the si-lnc-HOST2 1 was significantly lower than that in the blank group and si-CON group $(F \quad$ The results indicated that down-regulation of lnc-HOST2 inhibited the migration

Eff Inc- 1 on the invasion of MG-63 cells among the three groups

The ber of cells migrating to the bottom of the Transwell through the Matrigel in

ank o and si-CON group was $54.67 \pm 14.23$ and $51.92 \pm 10.45$, respectively $(P>$

The nu ber of cells that migrated to the bottom of the Transwell through the Matrigel

th thOST2 group was $35.64 \pm 13.86$, which was significantly lower than that in the

ak group and si-CON group (both $P<0.05$ ). The results showed that down-regulation of 11 'PST2 inhibited the invasion of MG-63 cells (Fig. 7).

Effect of Inc-HOST2 on the apoptosis of MG-63 cells among the three groups

Flow cytometry of PI-stained cells was used to detect the cell cycle distribution of MG63 cells when lnc-HOST expression was knocked down, and the results were as follows: the proportion of MG-63 cells in G1 phase among the blank group, si-CON group and si-lnc-HOST2 group were $(50.35 \pm 1.74) \%$, $(51.42 \pm 1.16) \%$ and $(67.23 \pm 1.26) \%$, respectively (Fig. 8). In the si-lnc-HOST2 group, cell cycle was primarily halted at G1 phase, while the proportion of the cells in S phase decreased. The proliferation of MG-63 cells with lnc-HOST knockdown was inhibited compared with that in the blank group and si-CON group $(P<0.05)$. There was no significant difference between the blank group and si-CON group $(P>0.05)$. 

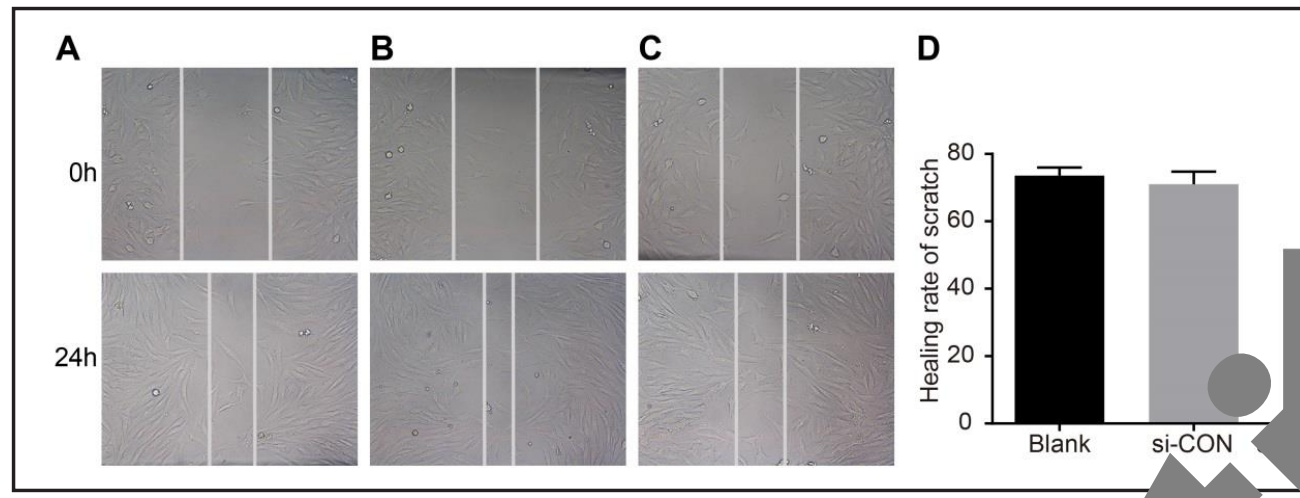

Fig. 6. Cell migrations of MG-63 cells by scratch test ( $\times 40$ magnification). A: Blank gro B: si-CON group (transfected with negative control siRNA); C: si-lnc-HOST2 group interfering lnc-HOST2 siRNA); D: the healing rate of MG-63 cells in the three gro assessed using the wound-scratch assay. * refers to $\mathrm{P}<0.05$ compared with the blan

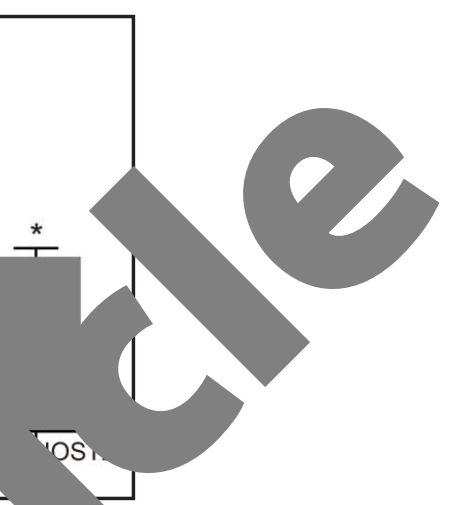
up and si-CON group.

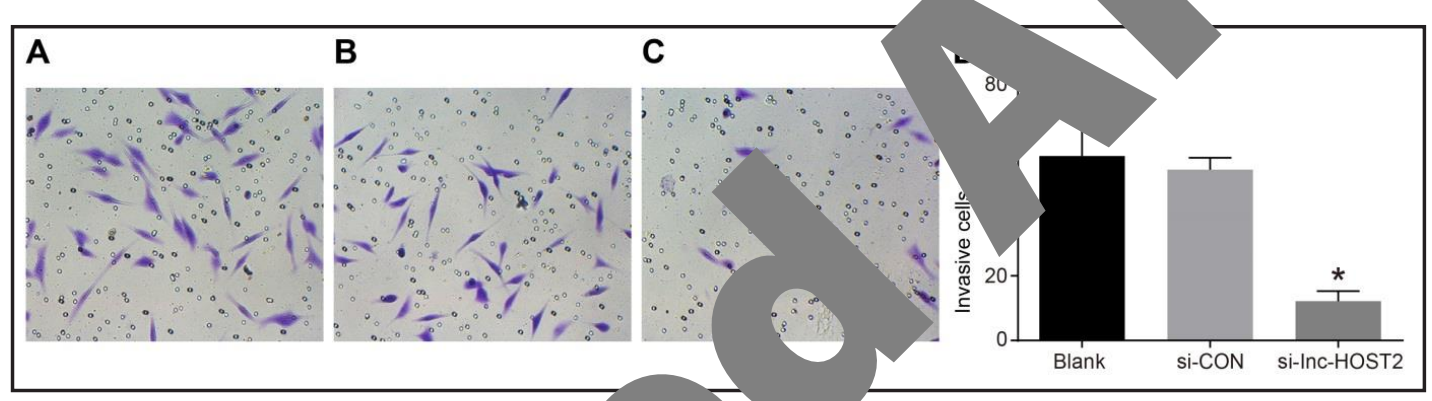

Fig. 7. Cell invasion of MG-63 cells as as ea the Transwell assay $(\times 200)$. A: Blank group (no transfection); B: si-CON group (transfected ati ontrol siRNA); C: si-lnc-HOST2 group (transfected with small interfering lnc-HOST transfection. * refers to $\mathrm{P}<0.05$ cor with tric vlank group and si-CON group.

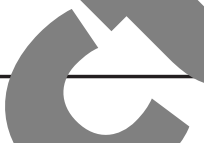

\section{A}
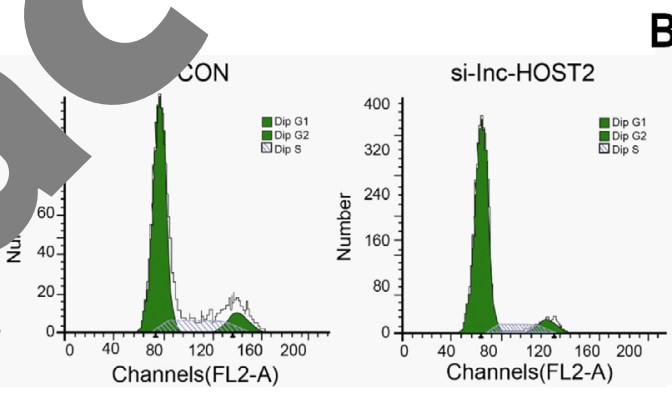

B

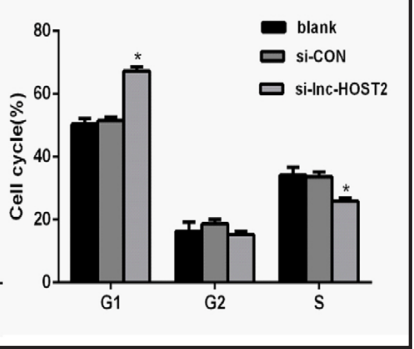

8. Gur cycle distribution of MG-63 cells among the three groups after a 48-h of transfection and

using flow cytometry with PI staining. A: Cell cycle distribution of MG-63 cells in the three oups. * refers to $\mathrm{P}<0.05$ compared with the blank group and si-CON group.

Flow cytometry with Annexin V/PI double staining was used to assess the number of apoptotic MG-63 cells after knocking down lnc-HOST expression, and the results were as follows: the apoptosis rates of the blank group, si-CON group and si-lnc-HOST2 group after $48 \mathrm{~h}$ of transfection were $(17.54 \pm 0.67) \%$, $(18.65 \pm 0.86) \%$ and $(26.75 \pm 1.84) \%$, respectively. Compared with the blank group and si-CON group, the si-lnc-HOST2 group exhibited a significantly increased apoptosis rate of MG-63 cells $(P<0.05)$. There was no 

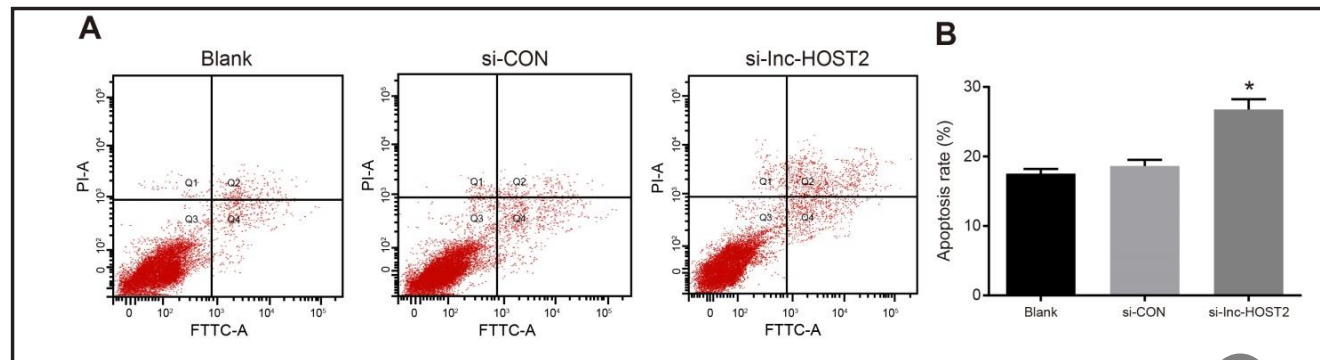

Fig. 9. Apoptosis of MG-63 cells among the three groups $48 \mathrm{~h}$ after transfection as assesucd cing cytometry with Annexin V/PI double staining. A: The apoptosis of MG-63 cells in the three transfection. B: apoptosis rates of MG-63 cells in the three groups after transfectio compared with the blank group and si-CON group.

significant difference between the blank group and si-CON group $r$ rate $(P>0.05)$ (Fig. 9). The results described above revea ${ }^{1}$ that do HOST2 significantly promoted the apoptosis of MG-63 $\mathrm{ce}^{\prime}$

\section{Discussion}

Osteosarcoma is one of the most common p. malignànt bone tumors in children. Treatment methods such as chemotherapy a aring surgery have been applied for osteosarcoma [17]. However, these treatn met induce increased risk of relapse and the development of metastasis in some $\quad 2]$. Understanding the mechanisms and underlying pathogenesis of oster nelp yield novel biomarkers for early detection and treatment. It has been di ed that lncRNAs are related to the occurrence and development of many $h, d$ may play potential roles in physiological processes $[18,19]$. In additio vious es have revealed the presence of differentially expressed lncRNAs in osteos and suggest that lncRNAs may be novel candidate biomarkers for the diag so of roma [20,21]. LncRNAs have been implicated in many cellular processe nd the dysregulation of lncRNAs could play an important role in osteosarcoma [22]. T he aim of this study was to determine the effects of lncHOST2 on the pr or ation, invasion and apoptosis of osteosarcoma cells.

In our sty vression of lnc-HOST2 was observed in both osteosarcoma cell lines and inical ee ns. The expression of lnc-HOST2 in osteosarcoma tissues was significant iigh that in adjacent normal tissues. Our data indicated that lnc-HOST2 could p. te the proliferation of osteosarcoma cells relative to osteosarcoma progression. a. that the expression of IncRNAs such as MEG3 was significantly decreased osarco as, which suggests that IncRNAs might function as tumor suppressors [23]. For asons, we hypothesized that lnc-HOST2 could be a promising biomarker and rap target for the treatment of osteosarcoma.

Furthermore, to study the effect of lnc-HOST2 on biological progression of osteosarcoma, sw oserved the proliferation, migration and invasion of MG-63 cells after inhibiting lncST2 expression. The results showed that down-regulation of lnc-HOST2 could effectively inhibit the proliferation, migration and invasion as well as promote apoptosis of osteosarcoma cells. Lnc-HOST2 has been reported to be highly expressed in human cancers, and lnc-HOST2 inhibits let-7b function, which could post-transcriptionally inhibit the expression of targets such as some oncogenes that regulate cell growth and motility [14]. In addition, HMGA2, c-Myc, Dicer and lmp3, all of which are targets of lnc-HOST2, appear to participate in cell cycle regulation and malignant transformation; however, HMGA2 has been primarily implicated in the pathogenesis of benign, mesenchymal tumors [24]. c-Myc is the most common oncogene involved in the regulation of cell cycle and promotes cell apoptosis [25]. Dicer is known as

\section{KARGER}




\section{Cellular Physiology Cell Physiol Biochem 2017;43:320-330 \begin{tabular}{ll|l} 
DOI: 10.1159/000480412 & O 2017 The Author(s). Published by S. Karger AG, Basel \\
www.karger.com/cpb
\end{tabular} \\ Wang et al.: Effects of Lncrna-HOST2 On Osteosarcoma Cells}

a central enzyme in microRNA processing and is important to produce mature microRNAs, which would regulate post-transcriptional gene expression [26]. Overexpression of lmp3 in calvarial osteoblasts, dermal fibroblasts, and bone marrow stromal stem cells stimulates osteo lineage differentiation in vitro [27]. For these reasons, we suggested that lnc-HOST2 could be a control factor not only in ovarian cancer but also in osteosarcoma cells; additiona the miRNA Let-7b plays a role in transcriptional regulation. Thus, the expression of HMGA and c-Myc as well as the proliferation, invasion and migration of tumor cells are promoted. Understanding lnc-HOST2/let-7b-dependent regulation may lead to alternative approac' for the diagnosis and cure of osteosarcoma. However, the concrete mechanism aflnc- $\mathrm{HC}$ still needs further study.

\section{Conclusion}

Taken together, lnc-HOST2 could be highly expressed specifically $i$ participate in regulating the migration, invasion and proliferation These processes might be closely associated with the de rment 0 Thus, Inc-HOST2 could be a new potential target for the tr the specific mechanism of how lnc-HOST2 functions in ost of adequate experimental data. Thus, the next step is to co plasmid to increase the levels of endogenou vression ar biological function of osteosarcoma cells in dep

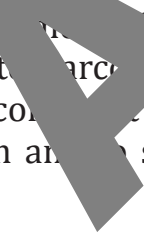
ignant tumors. steos ra and teosarcoma cells. 2

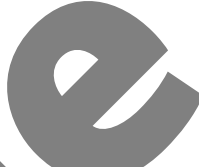

Acknowledgements

The authors are grateful to re w for tneir critical comments regarding the manuscript.

\footnotetext{
Allison DC, Carney SC, Ahlmann ER, Hendifar A, Chawla S, Fedenko A, Angeles C, Menendez LR: A meta-
nalysis of osteosarcoma outcomes in the modern medical era. Sarcoma 2012;2012:704872.

Sanchez Y, Huarte M: Long non-coding RNAs: challenges for diagnosis and therapies. Nucleic Acid Ther 2013;23:15-20.

Maruyama R, Suzuki H: Long noncoding RNA involvement in cancer. BMB Rep 2012;45:604-611.

Pan Y, Li C, Chen J, Zhang K, Chu X, Wang R, Chen L: The Emerging Roles of Long Noncoding RNA ROR (lincRNA-ROR) and its Possible Mechanisms in Human Cancers. Cell Physiol Biochem 2016;40:219-229.

-8 Wang L, Chen Z, An L, Wang Y, Zhang Z, Guo Y, Liu C: Analysis of Long Non-Coding RNA Expression Profiles in Non-Small Cell Lung Cancer. Cell Physiol Biochem 2016;38:2389-2400.

-9 Qiu ZL, Shen CT, Sun ZK, Wei WJ, Zhang XY, Song HJ, Luo QY: Circulating Long Non-Coding RNAs Act as Biomarkers for Predicting 131I Uptake and Mortality in Papillary Thyroid Cancer Patients with Lung Metastases. Cell Physiol Biochem 2016;40:1377-1390.
} 


\section{Cellular Physiology Cell Physiol Biochem 2017;43:320-330 \begin{tabular}{l|l} 
DOI: 10.1159/000480412 & Ond Biochemistry 2017 The Author(s). Published by S. Karger AG, Basel \\
wuww.karger.com/cpb
\end{tabular} \\ Wang et al.: Effects of Lncrna-HOST2 On Osteosarcoma Cells}

10 Li J, Wang X, Tang J, Jiang R, Zhang W, Ji J, Sun B: HULC and Linc00152 Act as Novel Biomarkers in Predicting Diagnosis of Hepatocellular Carcinoma. Cell Physiol Biochem 2015;37:687-696.

11 Li C, Chen J, Zhang K, Feng B, Wang R, Chen L: Progress and Prospects of Long Noncoding RNAs (IncRNAs) in Hepatocellular Carcinoma. Cell Physiol Biochem 2015;36:423-434.

12 Wang Y, Gao S, Liu G, Jia R, Fan D, Feng X: Microarray expression profile analysis of long non-coding RNAs human gastric cardiac adenocarcinoma. Cell Physiol Biochem 2014;33:1225-1238.

-13 Rangel LB, Sherman-Baust CA, Wernyj RP, Schwartz DR, Cho KR, Morin PJ: Characterization of novel human ovarian cancer-specific transcripts (HOSTs) identified by serial analysis of gene expression. Oncogene 2003;22:7225-7232.

14 Gao Y, Meng H, Liu S, Hu J, Zhang Y, Jiao T, Liu Y, Ou J, Wang D, Yao L, Liu S, Hui N: LncRNAcell biological behaviors in epithelial ovarian cancer through a mechanism involving microRN Mol Genet 2015;24:841-852.

15 Li BP, Liu JL, Chen JQ, Wang Z, Mao YT, Chen YY: Effects of siRNA-mediated silencing or leukelia- 1 on the biological behaviors and drug resistance of gastric cancer cells. Am 2015;7:2397-2411.

16 Kutty RK, Nagineni CN, Samuel W, Vijayasarathy C, Hooks JJ, Redmond TM: Infl. regulate microRNA-155 expression in human retinal pigment epitb cells by ac pathway. Biochem Biophys Res Commun 2010;402:390-395.

-17 Heare T, Hensley MA, Dell'Orfano S: Bone tumors: osteosarcoma 2009;21:365-372.

18 Liu H, Song G, Zhou L, Hu X, Liu M, Nie J, Lu S, Wu X Y, Tao L, Chen of LncRNA expression profiling in pdk1 gene knocko 2013;32:1497-1508.

19 Pandey AK, Agarwal P, Kaur K, Datta M: MicroRNAs Biochem 2009;23:221-232. Li JP, Liu LH, Li J, Chen Y, Jiang XW, Ouyang of long noncoding RNAs in human osteo significance in human osteos?

22 Sun XH, Yang LB, Geng XL, Way prognosis and promotes ce nuía. teosarcoma. Int J Clin Exp Pathol 2015;8:2994-3000.

23 Tian ZZ, Guo XJ, Zhao YN potential predictor bior 2015;8:15138-15142. gg Y: Ded expression of long non-coding RNA MEG3 acts as a
r in p^oression and poor prognosis of osteosarcoma. Int J Clin Exp Pathol

-24 Di Cello F, Hil Resar LM: $\mathrm{H}$ tes in transformation in human lung cancer. Mol Cancer Res 2008;6:743-750.

25 Peleng S, KY M: Many faces of c-MYC. Arch Biochem Biophys 2003;416:129-136.

-26 Fage Kasaj Neichert W, Stenzinger A, Elwali NE, Dietel M, Denkert C: Down-regulation of the mic processing enzyme Dicer is a prognostic factor in human colorectal cancer. Histopathology $12 ; 6.561$.

Z, Rios 、, Park CH, Taut AD, Jin Q, Sugai JV, Robbins PD, Giannobile WV: LIM domain protein-3 (LMP3)

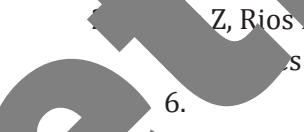
S with BMP7 to promote tissue regeneration by ligament progenitor cells. Gene Ther 2013;20:1- 